\title{
Incidence and Impact of Pulmonary Embolism During Severe COPD Exacerbation
}

\author{
Mohamed Fekih Hassen, Nejla Tilouche, Oussama Jaoued, and Souheil Elatrous
}

\begin{abstract}
BACKGROUND: Patients with COPD are at a high risk for pulmonary embolism (PE) because of systemic inflammation and co-existing comorbidities. We aimed to determine the incidence, risk factors, and impact of PE during COPD exacerbation requiring mechanical ventilation. METHODS: This prospective cohort study was conducted between March 2013 and May 2017. Subjects with severe COPD exacerbation requiring mechanical ventilation were included. A lower-limb ultrasonography or a multidetector helical computed tomography scan (MDCT) was performed according to Wells score. Subjects with ultrasonographic signs of phlebitis underwent MDCT to confirm PE. RESULTS: During the study period, 131 COPD subjects were admitted to the ICU for severe COPD exacerbation. The incidence of PE was $13.7 \%$. Factors independently associated with PE were increased sputum volume (odds ratio $[\mathrm{OR}]=\mathbf{0 . 1 0 6}, 95 \% \mathrm{CI} 0.029-0.385, P=.001)$, recent immobilization $\geq 7 \mathrm{~d}(\mathrm{OR}=\mathbf{5 . 0 2 4}$, 95\% CI 1.470-17.170, $P=.01)$, age $\geq 70$ y $(\mathrm{OR}=5.483,95 \%$ CI 1.269-23.688, $P=.02)$, and invasive mechanical ventilation at ICU admission $(\mathrm{OR}=3.615,95 \% \mathrm{CI} 1.005-13.007, P=.049)$. ICU mortality

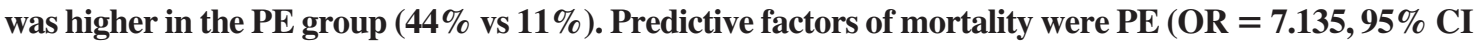
2.042-24.931, $P=.002$ ), SAPS II score at admission OR $=1.040,95 \%$ CI $1.005-1.077, P=.02$ ), and duration of mechanical ventilation $(O R=1.098,95 \%$ CI 1.044-1.154, $P<.001)$. CONCLUSION: $P E$ was found to be a common etiology of severe exacerbation of COPD, leading to high mortality. Age, invasive mechanical ventilation, and immobilization were risk factors for PE. Key words: pulmonary embolism; COPD; intensive care; mechanical ventilation; mortality; risk factors. [Respir Care 2019;64(12):1531-1536. () 2019 Daedalus Enterprises]
\end{abstract}

\section{Introduction}

COPD is the fourth leading cause of mortality and morbidity worldwide ${ }^{1}$ and represents a large economic burden for health care systems., ${ }^{2,3}$ COPD exacerbations are an episode of acute deterioration in respiratory symptoms accompanied by physiological changes and associated with an increase in airway and systemic inflammation. ${ }^{4,5} \mathrm{COPD}$ exacerbation may require intensive care admission and mechanical ventilation. Exacerbations are triggered by an

\footnotetext{
The authors are affiliated with the Intensive Care Unit, University Hospital Taher Sfar, Mahdia, Tunisia, and with Research Laboratory LR12SP15, University of Monastir, Tunisia.
}

The authors have disclosed no conflicts of interest.

Correspondence: Nejla Tilouche MD, Intensive Care Unit, University Hospital Tahar Sfar, Mahdia, Tunisia 5100. E-mail: tilouche.nejla@gmail.com.

DOI: $10.4187 /$ respcare.06661 infection in $50-70 \%$ of cases and by air pollution in $10 \%$ of cases, and up to $30 \%$ of cases ${ }^{6}$ are of unknown etiology. COPD is considered a predictor of venous thromboembolism because of immobilization, smoking, cardiac failure, and venous stasis. ${ }^{7-9}$ The incidence of pulmonary embolism (PE) during COPD exacerbation ranges from $3-29 \% 10-14$ and is even higher in postmortem reports. ${ }^{15,16}$ Although it is well known that patients with COPD are highly predisposed to developing PE, ${ }^{17}$ detailed information related to its development has not been prospectively analyzed. Thus, our aim in this study was to determine the incidence, risk factors, and impact of PE during exacerbation of COPD requiring mechanical ventilation.

\section{Methods}

This prospective cohort study was performed in the ICU of Taher Sfar University Hospital in Mahdia, Tunisia, between March 2013 and May 2017. The study protocol was approved by the hospital's ethics committee, and all in- 
cluded subjects' or their relatives' provided informed written consent. Inclusion criteria were admission to the ICU for severe COPD exacerbation according to the definition of the Global Initiative for Chronic Obstructive Lung Disease $^{18}$ with unknown etiology and necessitating mechanical ventilation within the first $24 \mathrm{~h}$. Subjects were mechanically ventilated if they had acute respiratory failure associated with respiratory acidosis: $\mathrm{pH}<7.35$ and $\mathrm{P}_{\mathrm{aCO}_{2}}>45 \mathrm{~mm} \mathrm{Hg}$ or severe hypoxemia. The diagnosis of COPD was based on medical history (previous diagnosis, hospitalizations, out-patient clinic visits) and the presence of air-flow limitation. COPD exacerbation was defined by the presence of at least 2 of the following symptoms: change in baseline dyspnea, cough, sputum production, or sputum purulence. ${ }^{19}$ Exclusion criteria included all other causes of respiratory deterioration (eg, pneumothorax, pneumonia, pleural effusion, pulmonary edema, or iatrogenic factor), renal failure (ie, serum creatinine $>1.5 \mathrm{mg} / \mathrm{dL}$ ), hypersensitivity to contrast material, or taking anticoagulant therapy for any cause.

\section{Study Intervention}

The Wells score ${ }^{20}$ was determined for each subject upon admission. A Wells score $>2$ indicates an intermediate or high clinical probability, in which case a multidetector computed tomographic (MDCT) angiography was performed. In all other cases, a lower-limb ultrasonography was performed; in the event of incomplete compressibility of the vein, an MDCT was used for final confirmation.

Angiography was performed with a 16-slice MDCT (tube voltage, $120 \mathrm{kV}$; tube current, $240 \mathrm{~mA}$ ) during a breathhold, with injection of $100 \mathrm{~mL}$ contrast material with a power injector at $3.5 \mathrm{~mL} / \mathrm{s}$, using a slice thickness of $3 \mathrm{~mm}$ and a reconstruction interval of $2 \mathrm{~mm}$. PE was confirmed if the contrast material outlined a partial or total filling defect. We did not use plasma D-dimer because the Ddimer assay in our hospital is not the quantitative enzymelinked sorbent assay, so it could not be used to rule out PE. Cardiac function was evaluated with echocardiography in case of shock at ICU admission or to help in diagnosing cardiac dysfunction as the cause of COPD.

The following data were collected for all subjects: demographic characteristics; comorbidities; baseline treatment; severity of illness estimated with the Simplified Acute Physiology Score (SAPS II); risk factors for PE; Anthonisen classification; clinical, radiological, electrocardiographic, and biochemical parameters on admission; all therapeutics administered (eg, mechanical ventilation, anticoagulation) duration of mechanical ventilation; ICU length of stay; and ICU mortality.

\section{Statistics}

Analyses were performed using a statistical software package (SPSS version 18.0, SPSS, Chicago, Illinois). Vari-

\section{QUICK LOOK}

\section{Current knowledge}

About $30 \%$ of episodes of COPD exacerbation are unexplained. COPD is a known risk factor for thromboembolism, but the incidence and impact of pulmonary embolism during severe exacerbations requiring mechanical ventilation have not been well investigated.

\section{What this paper contributes to our knowledge}

Pulmonary embolism was a frequent cause of unexplained COPD exacerbation requiring mechanical ventilation. Pulmonary embolism was more frequent in older subjects and those invasively ventilated at ICU admission. Systematic screening of patients with intermediate clinical probability may enable clinicians to detect more pulmonary embolism cases.

ables were expressed as mean $\pm \mathrm{SD}$ or as median (interquartile range) depending on the type of distribution, and categorical data were presented as a number and percentage. Baseline characteristics were compared using the chi-square test or Fisher exact test as appropriate for categorical variables. Continuous variables were compared with the Student $t$ test or Mann-Whitney test as appropriate. A $P$ value $<.05$ was considered statistically significant. A multiple logistic stepwise regression analysis including variables with $P<.20$ in the univariate analysis was conducted to determine predictive factors of PE and of mortality.

\section{Results}

During the study period, 361 patients were screened for inclusion. A total of 230 patients were excluded for different reasons (Fig. 1); 131 subjects with a mean age of $68 \pm 13$ years were included. Seventy-five (57\%) subjects had noninvasive ventilation (Table 1). The algorithm for $\mathrm{PE}$ diagnosis is shown in Figure 2.

According to the Wells criteria, 1 subject had high clinical probability, 58 subjects had intermediate clinical probability, and 72 subjects had a low clinical probability. Only 1 subject had a deep vein thrombosis on lower-limb ultrasonography. Echocardiography performed in 20 subjects with intermediate clinical probability ruled out left cardiac dysfunction. When performed in 1 subject with shock, the test showed acute cor pulmonale. The MDCT scan, carried out in 60 subjects, showed PE in 18 subjects (13.7\%). PE was segmental in 44\%.

One subject with shock had thrombolysis, and 2 subjects with PE developed cardiogenic shock after $24 \mathrm{~h}$ but 


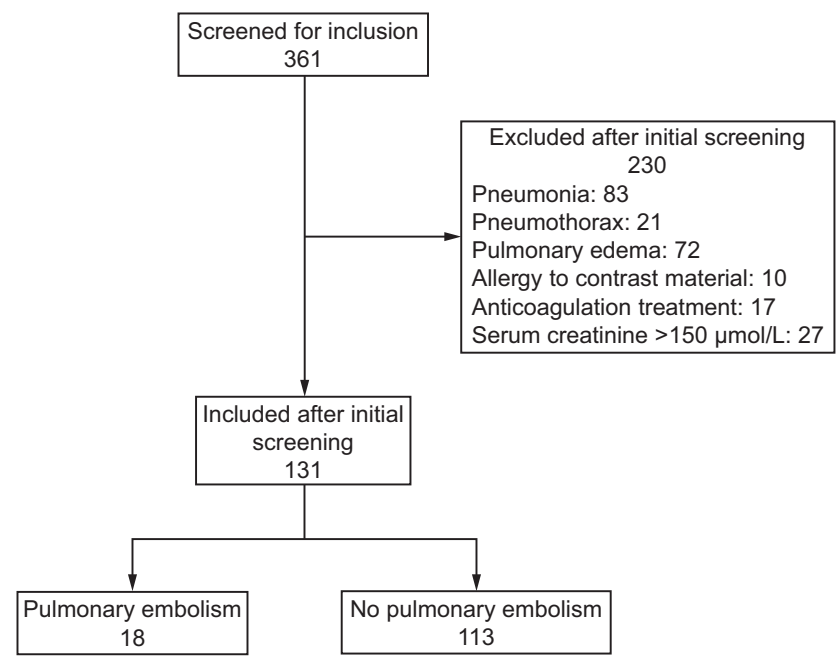

Fig. 1. Flow chart.

did not receive thrombolysis because of hemostasis disorder. At baseline, subjects with PE were significantly older, and more critically ill (SAPS II score: 35 (IQR, 21-42) vs 26 (IQR, 20-35), $P=0.036),(P=0.22)$. Heart rate and type 3 exacerbation of Anthonisen were significantly higher in the PE group. Electrocardiographic findings were similar in both groups, whereas chest radiograph findings showed more atelectasis and pleural effusion in the PE group (17\% vs $3 \%, P=.034$ and $38 \%$ vs $14 \%, P=.02$, respectively) (Table 2 ).

Immobilization for $\geq 7 \mathrm{~d}$ prior to ICU admission was more frequently reported in the PE group (56\% vs $15 \%$, $P<.001$ ). In the multivariate analysis, factors independently associated with the presence of PE were increased sputum volume (odds ratio $[\mathrm{OR}]=0.106,95 \%$ CI 0.029 $0.385, P=.001$ ), immobilization $\geq 7 \mathrm{~d}$ before ICU admission $(\mathrm{OR}=5.024,95 \%$ CI $1.470-17.170, P=.01)$, age $\geq 70$ y $(\mathrm{OR}=5.483,95 \%$ CI $1.269-23.688, P=.02)$, and the need for invasive mechanical ventilation at ICU admission $(\mathrm{OR}=3.615,95 \%$ CI 1.005-13.007, $P=.049)$ (Table 3).

In the PE group, 8 subjects died; death was related to septic shock in 5 cases and cardiogenic shock in 3 cases. In subjects without PE, 12 subjects died; death was related to septic shock in 10 cases and hypoxemia in 2 cases.

Mortality was significantly higher in the PE group (44\% vs $11 \%, P<.001$ ). (Table 1 ). After adjusting for age, SAPS II score, and $\mathrm{pH}$, the independent predictors of mortality were PE (OR $=7.135$, 95\% CI $2.042-$ 24.931, $P=.002$ ), duration of mechanical ventilation $(\mathrm{OR}=1.098,95 \%$ CI $1.044-1.154, P<.001)$, and SAPS II score $(\mathrm{OR}=1.040,95 \%$ CI $1.005-1.077$, $P=.02)$ (Table 4).

\section{Discussion}

In our study, $13.7 \%$ of subjects admitted to the ICU for severe COPD exacerbation had acute PE. Predisposing factors to PE included an age $>70$ years, immobilization, and invasive mechanical ventilation. PE was associated with significantly higher mortality.

The incidence of symptomatic PE in COPD patients ranges between 3\% and 29\%. ${ }^{10-14}$ Variations in reported incidence may be explained by differences in study designs and modalities of PE investigation. Indeed, in the study by Ristic et al, ${ }^{13}$ subjects with chronic hypoxemia admitted to the ICU were investigated with a protocol using D-dimer to refer subjects to lower-limb Doppler ultrasonography or MDCT. In a retrospective study, Bahloul et $\mathrm{al}^{10}$ determined the presence of PE using MDCT results in 51 COPD subjects. Akpinar et al ${ }^{12}$ and Tillie-Leblond et $\mathrm{al}^{14}$ included COPD subjects with mild to moderate exacerbation. Subjects in both studies underwent MDCT within $24 \mathrm{~h}$ of admission, and the prevalence of PE was $29.1 \%$ and $24.9 \%$, respectively. For Tillie-Leblond et al, ${ }^{14}$ the diagnosis of PE was confirmed with contrast-enhanced $\mathrm{CT}$ angiogram or a positive lower-leg ultrasound, while in 2 other studies, PE was excluded if the D-dimer test was negative. ${ }^{21,22}$ A systematic MDCT during COPD exacerbation could assist in finding more unsuspected PE cases, thus raising the incidence of $\mathrm{PE}$. In addition, variations in the incidence of PE may be caused by whether subsegmental defects on MDCT are considered clinically relevant in the inclusion of subjects with known risk factors for PE. The incidence of PE in subjects with intermediate probability was $29 \%$. In clinical practice, PE is actively sought in cases of high clinical probability; in other cases, D-dimer is used. Our results show that a more active screening for PE with MDCT is justified in subjects with COPD. PE is frequently described as asymptomatic ${ }^{23}$ because its symptoms are nonspecific, especially in COPD subjects, where even the most typical presentation (eg, dyspnea, cough, chest pain) merges with the usual presentation of severe exacerbations of other origins.

In our study, the absence of cardinal signs of bronchial infection and tachycardia were more frequent in subjects with PE, which matches the findings of Rutschmann et al. ${ }^{21}$ Other blood gas or electrocardiographic data were comparable between the 2 groups, and only the chest radiograph showed more abnormalities for the PE group.

Age and immobilization are known risk factors for PE in the general population. ${ }^{24} \mathrm{COPD}$ itself is a known risk factor for PE, and in these patients venous thromboembolism may be missing. ${ }^{24-26}$ Accordingly, COPD may induce pulmonary vascular alterations $\mathrm{s}^{27,28}$ and pulmonary hypertension, which increases vascular resistance and stagnation of blood flow.9,29 These disturbances mimic the hemody- 
Table 1. Baseline Characteristics of Subjects With and Without Pulmonary Embolism

\begin{tabular}{|c|c|c|c|c|}
\hline & All Subjects $(N=131)$ & $\mathrm{PE}(n=18)$ & No $\operatorname{PE}(n=113)$ & $P$ \\
\hline Age, y & $68 \pm 13$ & $75 \pm 7$ & $67 \pm 14$ & .005 \\
\hline Sex, males & $104(79)$ & $13(72)$ & $91(81)$ & .52 \\
\hline SAPS II & $27(21-38)$ & $35(21-42)$ & $26(20-35)$ & .036 \\
\hline \multicolumn{5}{|l|}{ Comorbid conditions } \\
\hline Hypertension & $48(37)$ & $9(50)$ & $39(35)$ & .20 \\
\hline Diabetes mellitus & $21(16)$ & $1(6)$ & $20(17)$ & .30 \\
\hline Cardiac failure & $29(22)$ & $7(39)$ & $22(20)$ & .07 \\
\hline ABCD classification & & & & .75 \\
\hline A & $5(4)$ & 0 & $5(4)$ & \\
\hline $\mathrm{B}$ & $91(69)$ & $13(72)$ & $78(69)$ & \\
\hline $\mathrm{C}$ & $2(1)$ & 0 & $2(2)$ & \\
\hline $\mathrm{D}$ & $33(25)$ & $5(28)$ & $28(25)$ & \\
\hline \multicolumn{5}{|l|}{ Dyspnea } \\
\hline At rest & $46(35)$ & $12(67)$ & $34(30)$ & .01 \\
\hline At daily activities & $85(65)$ & $6(38)$ & $79(70)$ & .005 \\
\hline Home oxygen therapy & $47(36)$ & $3(17)$ & $44(39)$ & .067 \\
\hline \multicolumn{5}{|l|}{ Clinical presentation } \\
\hline Chest pain & $16(12)$ & $3(17)$ & $13(12)$ & .22 \\
\hline Cough & $110(84)$ & $9(50)$ & $101(89)$ & $<.001$ \\
\hline \multicolumn{5}{|l|}{ Sputum } \\
\hline Increased volume & $90(69)$ & $5(28)$ & $85(75)$ & $<.001$ \\
\hline Purulence & $65(50)$ & $7(39)$ & $58(51)$ & .32 \\
\hline Syncope & $4(3)$ & $1(6)$ & $3(3)$ & .45 \\
\hline \multicolumn{5}{|l|}{ Anthonisen classification } \\
\hline Type 1 & $50(38)$ & $5(28)$ & $45(40)$ & .32 \\
\hline Type 2 & $39(30)$ & $3(17)$ & $36(32)$ & .19 \\
\hline Type 3 & $42(32)$ & $10(59)$ & $28(27)$ & .02 \\
\hline \multicolumn{5}{|l|}{ Physical examination } \\
\hline Frequency, breaths/min & $31 \pm 11$ & $30 \pm 4$ & $31 \pm 13$ & .89 \\
\hline Heart rate, beats/min & $101 \pm 18$ & $109 \pm 16$ & $100 \pm 18$ & .042 \\
\hline Systolic blood pressure, $\mathrm{mm} \mathrm{Hg}$ & $138 \pm 27$ & $134 \pm 36$ & $139 \pm 26$ & .68 \\
\hline Shock on ICU admission & $3(2)$ & $1(6)$ & $2(2)$ & .37 \\
\hline \multicolumn{5}{|l|}{ Blood gas analyses } \\
\hline $\mathrm{pH}$ & $7.29 \pm 0.08$ & $7.3 \pm 0.1$ & $7.29 \pm 0.07$ & .59 \\
\hline $\mathrm{P}_{\mathrm{aO}_{2}}, \mathrm{~mm} \mathrm{Hg}$ & $51 \pm 12$ & $51 \pm 11$ & $51 \pm 12$ & .86 \\
\hline $\mathrm{P}_{\mathrm{aCO}}, \mathrm{mm} \mathrm{Hg}$ & $76 \pm 13$ & $72 \pm 14$ & $79 \pm 13$ & .54 \\
\hline Mechanical ventilation & & & & .049 \\
\hline Invasive & $58(44)$ & $11(65)$ & $40(39)$ & \\
\hline Noninvasive & $75(57)$ & $6(35)$ & $62(61)$ & \\
\hline Duration of mechanical ventilation, $d$ & $5(3-10)$ & $6(2.7-15.7)$ & $5(3-10)$ & 69 \\
\hline Length of stay, $d$ & $8(5-13)$ & $9(4-20)$ & $8(6-12)$ & .86 \\
\hline Mortality & $20(15)$ & $8(44)$ & $12(11)$ & $<.001$ \\
\hline $\begin{array}{l}\text { Data are presented as } n(\%) \text {, mean } \pm \mathrm{SD} \text {, or media } \\
\text { PE }=\text { pulmonary embolism } \\
\text { SAPS II = Simplified Acute Physiology Score II }\end{array}$ & e range). & & & \\
\hline
\end{tabular}

namic disturbances caused by PE, which explains this predisposition. In addition, local and systemic inflammation can contribute to worsening comorbidities like diabetes mellitus and cardiovascular disease. ${ }^{18,30}$ Fibrinogen and C-reactive protein increase systemically during exacerbation and contribute to thrombotic events. ${ }^{31-33}$
In our study, mortality was significantly higher in the PE group, and PE was an independent risk factor for mortality. This finding matches those of other studies. ${ }^{10,34}$ Bahloul et al ${ }^{10}$ found higher mortality in the PE group (69.5\% vs $44 \%, P=.02)$, which can be explained by the presence of more organ failure in their subjects. 


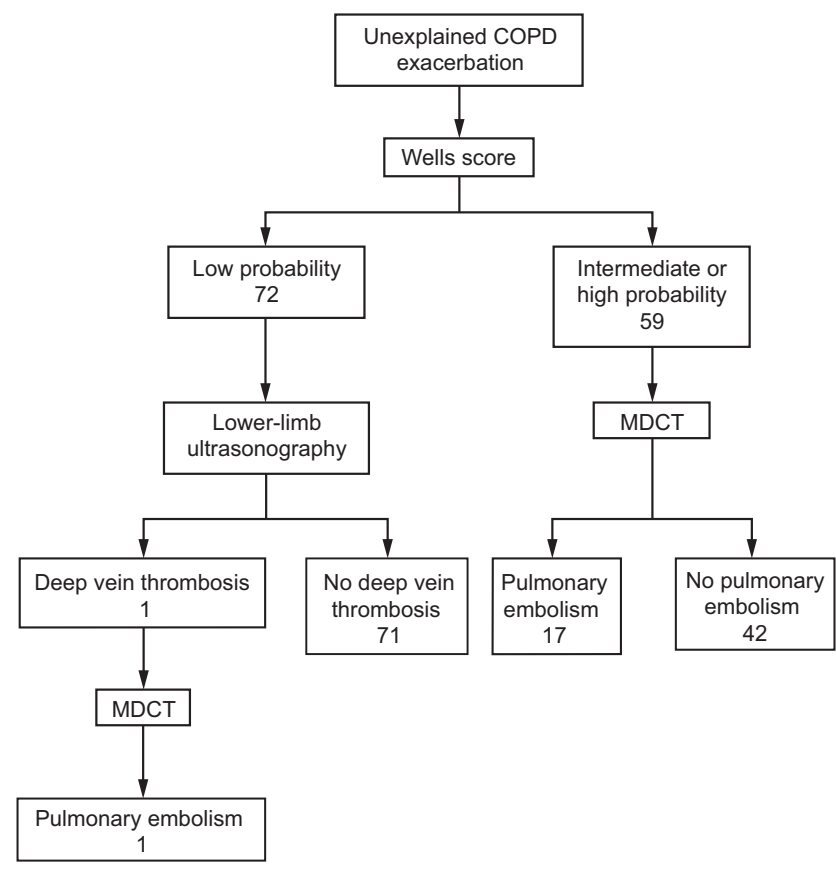

Fig. 2. Algorithm for diagnosis of pulmonary embolism. MDCT $=$ multidetector computed tomography.

Table 2. Comparison of Chest Radiograph and Electrocardiographic Changes

\begin{tabular}{lcccc}
\hline \hline & $\begin{array}{c}\text { All Subjects } \\
(N=131)\end{array}$ & $\begin{array}{c}\text { PE } \\
(n=18)\end{array}$ & $\begin{array}{c}\text { No PE } \\
(n=113)\end{array}$ & $P$ \\
\hline Chest radiograph & & & & \\
$\quad$ Atelectasis & $6(5)$ & $3(17)$ & $3(3)$ & .034 \\
$\quad$ Cardiomegaly & $16(12)$ & $3(17)$ & $13(12)$ & .46 \\
$\quad$ Elevated hemi diaphragm & $8(6)$ & $3(17)$ & $5(4)$ & .07 \\
$\quad$ Pleural effusion & $23(18)$ & $7(38)$ & $16(14)$ & .02 \\
Electrocardiogram & & & & \\
$\quad$ Atrial fibrillation & $12(9)$ & $4(22)$ & $8(7)$ & .061 \\
$\quad$ Right bundle branch & $64(49)$ & $11(61)$ & $53(47)$ & .26 \\
$\quad$ Negative T wave & $27(21)$ & $4(22)$ & $23(20)$ & $>.99$ \\
S1Q3 & $2(2)$ & $0(0)$ & $2(2)$ & $>.99$ \\
& & & & \\
Data are presented as $n(\%)$. & & & & \\
PE = pulmonary embolism & & & & \\
\hline
\end{tabular}

Mortality in our subjects was attributed to PE in only 3 cases. The other causes of mortality were nosocomial infection, septic shock, iatrogenic pneumothorax, and the severity at admission (65\% of our subjects with PE required invasive ventilation and had a median SAPS II score of 35). Our study has some limitations worth noting. First, we used lower-limb ultrasonography to rule out PE in subjects with low probability, which lacks sensitivity. Our choice was dictated by the absence of valid D-dimer testing in our hospital. Therefore, we may have missed some cases of PE. Second, we cannot exclude possible cases of undiagnosed subsegmental emboli on the MDCT,
Table 3. Factors Associated With Pulmonary Embolism

\begin{tabular}{lll}
\hline \hline \multicolumn{1}{c}{ Variables } & Odds Ratio (95\% CI) & \multicolumn{1}{c}{$P$} \\
\hline Increased sputum volume & $0.106(0.029-0.385)$ & .001 \\
Immobilization $>7 \mathrm{~d}$ & $5.024(1.470-17.170)$ & .01 \\
Age $\geq 70$ y & $5.483(1.269-23.688)$ & .02 \\
Invasive mechanical ventilation & $3.615(1.005-13.007)$ & .049
\end{tabular}

Data obtained with logistic regression.

Table 4. Multivariate Analysis: Predictive Factors of Mortality

\begin{tabular}{llc}
\hline \hline \multicolumn{1}{c}{ Variables } & Odds Ratio (95\% CI) & \multicolumn{1}{c}{$P$} \\
\hline Pulmonary embolism & $7.135(2.042-24.931)$ & .002 \\
Duration of mechanical ventilation & $1.098(1.044-1.154)$ & $<.001$ \\
SAPS II & $1.040(1.005-1.077)$ & .02
\end{tabular}

SAPS II = Simplified Acute Physiology Score II

which could underestimate the incidence. Finally, echocardiography was performed in only 21 subjects, but this exam is not recommended during PE without shock or hypotension because it is difficult to perform during the acute phase of severe exacerbation and because signs of right ventricular dysfunction are also found in COPD subjects without PE.

\section{Conclusions}

PE in COPD exacerbation was frequent and was associated with higher mortality. The diagnosis of PE should be considered in elderly and sedentary patients with COPD, especially those requiring invasive mechanical ventilation for a severe exacerbation.

\section{REFERENCES}

1. Murray CJ, Lopez AD. Mortality by cause for eight regions of the world: Global Burden of Disease Study. Lancet 1997;349(9061): 1269-1276.

2. Mannino DM, Homa DM, Akinbami LJ, Ford ES, Redd SC. Chronic obstructive pulmonary disease surveillance-United States, 19712000. Respir Care 2002;47(10):1184-1199.

3. Mannino DM, Homa DM, Akinbami LJ, Ford ES, Redd SC. Chronic obstructive pulmonary disease surveillance-United States, 19712000. MMWR Surveill Summ 2002;51(6):1-16.

4. Wedzicha JA, Seemungal TA, MacCallum PK, Paul EA, Donaldson GC, Bhowmik A, et al. Acute exacerbations of chronic obstructive pulmonary disease are accompanied by elevations of plasma fibrinogen and serum IL-6 levels. Thromb Haemost 2000;84(2):210-215.

5. Hurst JR, Perera WR, Wilkinson TM, Donaldson GC, Wedzicha JA. Systemic and upper and lower airway inflammation at exacerbation of chronic obstructive pulmonary disease. Am J Respir Crit Care Med 2006;173(1):71-78.

6. Sapey E, Stockley RA. COPD exacerbations. 2: aetiology. Thorax 2006;61(3):250-258. 


\section{Pulmonary EMbOLISM IN COPD}

7. Ambrosetti M, Ageno W, Spanevello A, Salerno M, Pedretti RF. Prevalence and prevention of venous thromboembolism in patients with acute exacerbations of COPD. Thromb Res 2003;112(4):203-207.

8. Moheimani F, Jackson DE. Venous thromboembolism: Classification, risk factors, diagnosis, and management. ISRN Hematol 2011; 2011:124610.

9. Behr J, Ryu JH. Pulmonary hypertension in interstitial lung disease. Eur Respir J 2008;31(6):1357-1367.

10. Bahloul M, Chaari A, Tounsi A, Baccouche N, Abid H, Chtara K, et al. Incidence and impact outcome of pulmonary embolism in critically ill patients with severe exacerbation of chronic obstructive pulmonary diseases. Clin Respir J 2015;9(3):270-277.

11. Akgun M, Meral M, Onbas O, Araz O, Koplay M, Aslan S, et al. Comparison of clinical characteristics and outcomes of patients with COPD exacerbation with or without venous thromboembolism. Respiration 2006;73(4):428-433

12. Akpinar EE, Hosgun D, Akpinar S, Atac GK, Doganay B, Gulhan M. Incidence of pulmonary embolism during COPD exacerbation. J Bras Pneumol 2014;40(1):38-45.

13. Ristic L, Rancic M, Radovic M, Ciric Z, Kutlesic Kurtovic D. Pulmonary embolism in chronic hypoxemic patients with and without secondary polycythemia-analysis of risk factors in prospective clinical study. Med Glas (Zenica) 2013;10(2):258-265.

14. Tillie-Leblond I, Marquette CH, Perez T, Scherpereel A, Zanetti C, Tonnel AB, et al. Pulmonary embolism in patients with unexplained exacerbation of chronic obstructive pulmonary disease: prevalence and risk factors. Ann Intern Med 2006;144(6):390-396.

15. Baum GL, Fisher FD. The relationship of fatal pulmonary insufficiency with cor pulmonale, right sided mural thrombi and pulmonary emboli: a preliminary report. Am J Med Sci 1960;240:609-612.

16. Neuhaus A, Bentz RR, Weg JG. Pulmonary embolism in respiratory failure. Chest 1978;73(4):460-465.

17. Poulsen SH, Noer I, Moller JE, Knudsen TE, Frandsen JL. Clinical outcome of patients with suspected pulmonary embolism. A follow-up study of 588 consecutive patients. J Intern Med 2001;250(2): 137-143.

18. Global Initiative for Chronic Obstructive Lung Disease (GOLD): 2017 update. Available from www.goldcopd.org. Accessed April 26, 2019.

19. Celli BR, MacNee W, Force AET. Standards for the diagnosis and treatment of patients with COPD: a summary of the ATS/ERS position paper. Eur Respir J 2004;23(6):932-946.

20. Wells PS, Anderson DR, Rodger M, Ginsberg JS, Kearon C, Gent M, et al. Derivation of a simple clinical model to categorize patients probability of pulmonary embolism: increasing the models utility with the SimpliRED D-dimer. Thromb Haemost 2000;83(3):416-420.
21. Rutschmann OT, Cornuz J, Poletti PA, Bridevaux PO, Hugli OW, Qanadli SD, et al. Should pulmonary embolism be suspected in exacerbation of chronic obstructive pulmonary disease? Thorax 2007; 62(2):121-125

22. Mispelaere D, Glerant JC, Audebert M, Remond A, Sevestre-Pietri MA, Jounieaux V. [Pulmonary embolism and sibilant types of chronic obstructive pulmonary disease decompensations]. Rev Mal Respir 2002;19(4):415-423.

23. Sidney S, Sorel M, Quesenberry CP Jr, DeLuise C, Lanes S, Eisner MD. COPD and incident cardiovascular disease hospitalizations and mortality: Kaiser Permanente Medical Care Program. Chest 2005; 128(4):2068-2075.

24. Borvik T, Braekkan SK, Enga K, Schirmer H, Brodin EE, Melbye H, et al. COPD and risk of venous thromboembolism and mortality in a general population. Eur Respir J 2016;47(2):473-481.

25. Bertoletti L, Quenet S, Mismetti P, Hernandez L, Martin-Villasclaras $\mathrm{JJ}$, Tolosa C, et al. Clinical presentation and outcome of venous thromboembolism in COPD. Eur Respir J 2012;39(4):862-868.

26. Kubota Y, London SJ, Cushman M, Chamberlain AM, Rosamond WD, Heckbert SR, et al. Lung function, respiratory symptoms and venous thromboembolism risk: the Atherosclerosis Risk in Communities Study. J Thromb Haemost 2016;14(12):2394-2401.

27. Wright JL, Petty T, Thurlbeck WM. Analysis of the structure of the muscular pulmonary arteries in patients with pulmonary hypertension and COPD: National Institutes of Health nocturnal oxygen therapy trial. Lung 1992;170(2):109-124

28. Magee F, Wright JL, Wiggs BR, Pare PD, Hogg JC. Pulmonary vascular structure and function in chronic obstructive pulmonary disease. Thorax 1988;43(3):183-189.

29. Chaouat A, Naeije R, Weitzenblum E. Pulmonary hypertension in COPD. Eur Respir J 2008;32(5):1371-1385.

30. Sinden NJ, Stockley RA. Systemic inflammation and comorbidity in COPD: a result of 'overspill' of inflammatory mediators from the lungs? Review of the evidence. Thorax 2010;65(10):930-936.

31. Saghazadeh A, Rezaei N. Inflammation as a cause of venous thromboembolism. Crit Rev Oncol Hematol 2016;99:272-285.

32. Esmon CT. The interactions between inflammation and coagulation. Br J Haematol 2005;131(4):417-430.

33. Alkim H, Koksal AR, Boga S, Sen I, Alkim C. Etiopathogenesis, prevention, and treatment of thromboembolism in inflammatory bowel disease. Clin Appl Thromb Hemost 2017;23(6):501-510.

34. Laporte S, Mismetti P, Decousus H, Uresandi F, Otero R, Lobo JL, et al. Clinical predictors for fatal pulmonary embolism in 15,520 patients with venous thromboembolism: findings from the Registro Informatizado de la Enfermedad TromboEmbolica venosa (RIETE) Registry. Circulation 2008;117(13):1711-1716. 